\title{
3 Research Square

\section{Prevalence of smoking and smoking predictors among adolescents in Qassim, Saudi Arabia: Does the Healthy City Program make any Difference?}

Ibrahim Alasqah ( $\sim$ i.alasqah@gmail.com )

School of Health, University of New England, Armidale, NSW 2351, Australia https://orcid.org/00000002-0316-1374

\section{Ilias Mahmud}

Department of Public Health, College of Public Health and Health Informatics, Qassim University, Al Bukairiyah, 51452, Al Qassim, Saudi Arabia https://orcid.org/0000-0003-1330-7813

\section{Leah East}

School of Health, University of New England, Armidale, NSW 2351, Australia

Kim Usher

School of Health, University of New England, Armidale, NSW 2351, Australia

\section{Research Article}

Keywords: Adolescents, smoking, Saudi Arabia, Healthy City Program

Posted Date: July 21 st, 2020

DOI: https://doi.org/10.21203/rs.3.rs-45211/v1

License: (c) (1) This work is licensed under a Creative Commons Attribution 4.0 International License. Read Full License

Version of Record: A version of this preprint was published on January 6th, 2021. See the published version at https://doi.org/10.1007/s10389-020-01449-y. 


\section{Abstract}

Aim: To compare the prevalence of smoking and smoking predictors among adolescents between cities running a healthy city program (HCP cities) and the cities that are not running such a program (NHCP cities) in the Qassim region, Saudi Arabia.

Subject and Methods: A cross-sectional survey using a self-reported questionnaire on the prevalence of smoking and smoking predictors among adolescents in Qassim region, Saudi Arabia was undertaken between April and September 2017. Using multi-staged cluster sampling, probability proportionate to the size, we surveyed 364 adolescents from three HCP cites and 769 adolescents from three NHCP cities.

Results: The overall prevalence of smoking among school-aged adolescents in Qassim is $5.2 \%$ (95\% Cl: 3.9-6.5). Smoking prevalence among adolescents in the HCP cities is $8.8 \%$ (95\% Cl: 5.9-11.7); while in the NHCP cities it is 3.5\% (95\% Cl: 2.2-4.8). The prevalence of at least one smoker among close friends in HCP and NHCP cities is $67.3 \%$ (62.5-72.1) and 72.2\% (69-75.3), respectively. The prevalence of at least one smoker in the family of the adolescents in HCP and NHCP cities is 58\% (52.9-63.1) and $44.3 \%$ (40.847.9), respectively. Among the socio-demographic variables, smoking is significantly associated with gender (OR: .08) *, age (OR: 1.61) and academic performance (OR: .27). Prevalence of smoking among adolescents is significantly higher in HCP cities than in NHCP cities (OR: 3.03; 95\% Cl: 1.7-5.4).

Conclusion: Prevalence of smoking and key smoking risk factors were found to be higher in cities implementing the healthy city program, despite exposure to an anti-smoking campaign being higher in these cities. Given these findings, we recommend further in-depth evaluation of the program.

\section{Background}

Tobacco use during adolescence is associated with adverse health effects later in life. Adolescence is the most critical period of life and is accompanied by rapid physical, psychological and emotional developments and changes, and smoking at this age can be more harmful to adolescents' health by increasing the risk of developing chronic diseases. Research reports that people who commence smoking at an early age are more likely to continue to smoke into their adults years(So and Yeo 2015). While smoking prevalence is declining in developed countries, the prevalence of smoking is increasing in many developing counties including Saudi Arabia ( $\mathrm{Ng}$ et al. 2014). The Kingdom of Saudi Arabia (KSA) is a developing country with a relatively high prevalence of smoking among the population. Recent estimates indicate that approximately $20 \%$ of Saudi Arabian citizens are smokers and similar rates of tobacco smoking have been reported among adolescents.

The Ministry of Health in Saudi Arabia has implemented a variety of public health programs to improve population health, yet the effectiveness of these programs has not been evaluated. The World Health Organisation's (WHO) Healthy City project (HCP) was launched in Saudi Arabia in 1998. The program has been expanding through various stages and currently 30 cities from across the country have joined the program, five of them have been recognized by the WHO as healthy cities. The aim of the HCP is to 
improve the health and quality of life of city residents on a continuous basis through continual community participation and inter-sectoral collaboration. Yet, to date, no published research has examined the impact of the HCP on adolescents' health risk behaviours, particularly smoking. Therefore, the current study aimed to explore the smoking-related characteristics of adolescents in secondary schools living in three cities that have implemented the HCP and compare those with adolescents living in three cities that have not implemented the project (NHCP) within the Qassim region, Saudi Arabia. The study also aimed to determine variables that predict smoking among the sample.

\section{Methods}

\section{Study design and settings}

This paper is part of a larger cross-sectional survey to evaluate the impact of the HCP among adolescents in Qassim, Saudi Arabia between April and September 2017. In this study, we investigated differences in the prevalence of smoking and smoking risk factors between HCP and NHCP cities. The Qassim region is one of the 13 administrative regions of the KSA and is located in the centre of the country. It consists of 10 cities with an estimated population of 1.37 million (GAS 2015). Approximately one fifth (19.7\%) of the population is aged between 10 and 19 years. The Human Research Ethics Committee of the University of New England approved the study (number HE17-021). Permission to conduct this study was also received from Qassim Education (approval number 38644423). Additionally, completion of the questionnaire was considered informed implied consent.

\section{Sampling and data collection}

We used multi-staged cluster sampling to recruit $10^{\text {th }}$ to $12^{\text {th }}$ grade high school students aged between 15 and 19 years. First, we purposively selected six cities within the Qassim region, Saudi Arabia. These cities were Buraidah, Unaizah, Alrass, Albukayriah, Albadea and Almedhnab. Three of these cities (Buraidah, Unaizah and Alrass) were running the healthy city programme while the others were not. We recruited 1,133 participants. We stratified the schools by geographical location, type of school and gender of students to yield a representative sample of 1,133 students. We randomly selected students, probability proportionate to the size, from the randomly selected schools. We used a self-reported structured questionnaire. The questionnaire covered aspects of smoking behaviours including practices, knowledge and attitudes, and socio-demographic characteristics. In this study, non-smokers included those who had never smoked any tobacco product, had tried it only once or who had stopped smoking; while, smokers included those who had occasionally smoked or had smoked cigarettes or another tobacco product every day over the previous 30 days. Data were collected between April and September 2017. The first author collected data from the male students; while a trained female research assistant collected data from the female students. Detailed instructions on completing the questionnaire were written in the questionnaire and verbal explanations were given to potential participants. Students recorded their responses on the questionnaire without any assistance. No identifying data were collected to ensure anonymity. Students 
who were absent during data collection and students aged less than 15 years or more than 19 years were excluded from the study.

\section{Statistical analysis}

IBM SPSS Statistics for Windows (version 22.0) (Armonk, NY: IBM Corp.) was utilized for data entry and analysis. Data were screened for missing values, outliers and collinearity. We performed descriptive analysis of socio-demographic variables by the type of cities. All socio-demographic variables were categorical; hence, proportion and frequency were computed. For prevalence estimate of smoking and smoking risk factors we computed proportion with $95 \%$ confidence interval (Cl). Multivariable logistic regression was used to investigate the socio-demographic determinants of smoking among adolescents. Another multivariable logistic regression analysis was also performed to investigate the differences in smoking prevalence between HCP and NHCP cities. Simple logistic regression was also performed to investigate the differences in smoking-related factors between HCP and NHCP cities. We computed the odds ratio (OR) with $95 \% \mathrm{Cl}$ for all logistic regression analysis

\section{Results}

\section{Characteristics of participants}

We surveyed 364 adolescents from the three cities implementing the HCP and 769 adolescents from another three cities which were not implementing that program. However, following data cleaning, we retained 750 participants from the cities which were not implementing the HCP and 358 participants from the HCP cities for further analysis. Participants were excluded for not meeting our inclusion criteria or for not responding to more than $10 \%$ of the questions. Table 1 presents socio-demographic characteristics of the participants. More than half of the participants in both groups were females: $414(55 \%)$ in NHCP and 194 (54\%) in HCP. Most of the participants in both groups were between 17 and 19 years old: 470 (66\%) in NHCP and $227(63 \%)$ in HCP. Participants were randomly selected from $10^{\text {th }}$ to $12^{\text {th }}$ grades in high schools. Most of the participants in both groups were enrolled in public schools: 627 (84\%) in NHCP and $317(89 \%)$ in HCP. More than half of the participants in both groups reported that they had excellent academic performance: 438 (58\%) in NHCP and 224 (63\%) in HCP. The majority of participants in both groups resided with both parents: 649 (87\%) in NHCP and 315 (88\%) in HCP. The percentage of fathers of the participants with at least college education was $41 \%(n=304)$ for those not exposed to HCP and $44 \%$ $(n=157)$ for those in HCP. Most of the mothers of those of whom were not exposed to the HCP had at most upper secondary education ( $n=353 ; 47 \%)$, while most of the mothers of those in HCP had at least college education ( $n=160 ; 45 \%)$. Most of the participants who were not exposed to the HCP had an estimated combined family monthly income $\leq 3999$ USD $(n=293 ; 39 \%)$, while those in HCP did not indicate the estimated combined family monthly income $(n=134 ; 37 \%)$.

\section{Prevalence of smoking and smoking risk factors among adolescents}


The prevalence of smoking and smoking risk factors among adolescents in the Qassim region is presented in Table 2. Prevalence of smoking among adolescents in the Qassim region was $5.2 \%$ ( $95 \% \mathrm{Cl}$ : 3.9-6.5\%). A higher prevalence of smoking was observed in the cities running the HCP (8.8\%) than in the cities without this program (3.5\%). We found that $48.7 \%$ of adolescents in the Qassim region had at least one smoker in their family. Again, prevalence of at least one smoker in family was higher in the cities running a $\mathrm{HCP}, 58 \%$, compared to $44.3 \%$ in other cities. However, prevalence of at least one smoker among close friends was higher in cities not running the HCP: $67.3 \%$ in healthy cities compared to $72.2 \%$ in other cities. Overall, the prevalence of having at least one smoker friend was $70.6 \%$ in the Qassim region. Regarding attitude towards banning smoking in public places, $93.7 \%$ of adolescents in healthy cities and $93 \%$ in other cities were in favour of this, with a regional rate of $93.2 \%$. In the Qassim region, $66.1 \%$ of current adolescent smokers reported that they had tried to quit in the previous year. This rate was higher in cities not implementing the HCP $(69.9 \%)$ than in the cities implementing the program (60.8\%). Thirty-eight point five per cent of adolescent smokers in the Qassim region believed that they could quit smoking if they wanted to. This rate is higher in healthy cities- $40.9 \%$ compared to $36.1 \%$ in other cities. Overall, $52.4 \%$ of adolescents mentioned that they knew where to seek support if they wanted to quit smoking. This rate is higher in healthy cities, $53.3 \%$, compared to $52 \%$ in other cities. In the previous year, $42.5 \%$ of adolescents in the Qassim region were exposed to antismoking campaigns. This exposure rate was higher in healthy cities (47.8\%) than other cities $(40.1 \%)$. In healthy cities, $51.1 \%$ adolescents mentioned that their parents discussed the harmful effects of smoking with them. This rate is $47.6 \%$ in other cities with an overall regional rate of $48.7 \%$. In healthy cities $86.5 \%$ and in other cities $83 \%$ mentioned that the harmful effect of smoking was discussed in their school. Only $16.5 \%$ of adolescents in the Qassim region believed that smokers have more friends than non-smokers. This figure is almost the same irrespective of the type of the city. Majority of adolescents $95.7 \%$ believed that smoking was harmful to their health. This rate was higher in healthy cities $(97.3 \%)$ than in other cities (94.9\%). $26.5 \%$ of adolescents believed that smoking makes one appear attractive. This figure was almost the same irrespective of the type of city. $32.8 \%$ of adolescents in the Qassim region believed that smoking gave one a feeling of independence. This belief was higher in healthy cities (38.7\%) compared to other cities (30\%).

\section{Logistic regression analysis of adolescents' current smoking behaviour by their socio-demographic variables}

We have investigated socio-demographic determinants of smoking among adolescents in the Qassim region. Analysis of results of this multivariable model are presented in Table 3. We found that gender, age, type of school and academic performance were associated with adolescents' current smoking behaviour. The odds of smoking among females were .08 times less than the odds of smoking among males. With each year's increase in age the odds of smoking increased by 1.61 times. The odds of smoking were 2.33 times greater in private schools compared to 1 in public schools. The odds of smoking among the higher academic achievers were .27 times lower than the odds of smoking among the students who achieved a lower grade. 
We investigated the effect of the healthy city program on adolescents' current smoking behaviour. This logistic regression analysis is presented in Table 4. We found that the odds of smoking among adolescents in healthy cities was 3.03 times greater than the odds of smoking among adolescents in other cities, when adjusted for type of school, gender, age and academic performance.

\section{Odds of smoking risk factors among adolescents by type of city health program}

We also investigated smoking risk factors among adolescents by the type of cities HCP and NHCP. The analysis of results is presented in Table 5. Among different environmental and attitudinal risk factors, we found that the prevalence of at least one smoker in the family, exposure to an antismoking campaign and belief that smoking gives a feeling of independence had statistically significant differences between cities. We found that in the healthy cities, the odds of having a smoker in the adolescents' family were 1.73 times greater than the other cities. The odds of the belief that smoking gives a feeling of independence were higher (OR: 1.47) in the healthy cities than in the other cities. However, we found that the odds of exposure to any antismoking campaign in the previous year were higher (OR: 1.37) in the healthy cities than in other cities.

\section{Discussion}

This study segregated the adolescents into two major groups which included those exposed to the HCP and those not exposed to the program. With regards to smoking, adolescents were classified as current smokers or non-smokers. Current smokers included anyone who occasionally or regularly smoked any tobacco products in the previous 30 days. Non-smokers included adolescents who had never smoked, who had stopped smoking or who had just tried tobacco smoking a few times but had not smoked a single cigarette in the previous 30 days.

We found that the prevalence of smoking among adolescents in Qassim was $5.2 \%$. This estimate is much lower than the estimates suggested by previous studies in Saudi Arabia. Al Nohair estimated the prevalence of smoking among adolescents in Qassim region at 23.6\%, based on data collected between January and June 2014 (Al Nohair 2017). However, Al Nohair included students aged 13 to 21 years, while we included only students aged 13 to 19 years. Additionally, our study findings suggest that with a year's increase in age the odds of smoking increase 1.61 times. In the current study, the prevalence of participants from the healthy city who stated they had the ability to quit smoking was $40.9 \%$ versus $30.1 \%$ in non-healthy cities. Chapman and MacKenzie (2012) stated that those who smoke need specific support in smoking cessation particularly considering smoking cessation can be difficult without support. Given the higher prevalence of smoking among those who were exposed to the HCP, we hypothesize that the HCP was not particularly effective in convincing smokers to quit.

In the present study, the participants' gender had an association with adolescents' current smoking behaviour. The odds of smoking among females was .08 times which is less than the odds of smoking among males. A study among middle school students conducted in Jeddah, Saudi Arabia, also revealed that gender had been associated with students' attitudes and social influences towards tobacco 
consumption (Park et al. 2012). Similar findings were reported in Jeddah among middle school students (Al Agili and Park 2012), and in Riyadh among adolescents (Al-Makadma et al. 2015). The study by Amin et al. (2010) also demonstrated that smoking in males was higher in prevalence than in females in secondary schools in Al-Hassa, Saudi Arabia. Similar findings were reported among 16- to 18-year-old adolescents, where the prevalence of smoking was $31.2 \%$ for males and $8.9 \%$ for females (Al Ghobain et al. 2011).

In our study, the prevalence of participants who felt that smoking made them attractive or feel independent was $26.5 \%$ and $32.8 \%$, respectively. Of note, the influence of the society was found to be significantly associated with tobacco consumption among Saudi middle school students (Park et al. 2012). A previous study in Dammam city showed that seeing someone smoking was more likely to influence a female university student to smoke (Ansari and Farooqi 2017).

The prevalence of having friends who smoke was higher in the cities without the health programs compared to healthy cities (72.2\% vs. $67.3 \%$ ), with an overall prevalence of $70.6 \%$ in the Qassim region. Friends who smoke has been found to influence adolescents to practice smoking by several studies conducted in Saudi Arabia (Al-Zalabani and Kasim 2015; Alsubaie 2018; Fida and Abdelmoneim 2013). Similar findings have been reported among students in King Faisal University by Al-Mohamed and Amin (2010), and among students in three other universities in the Kingdom by Almogbel et al. (2013). A study among medical students also showed that imitation of behaviours from the environment and the influence of peers were closely associated with smoking (Al-Kaabba et al. 2011). Being with friends who smoke has been shown to encourage boys and girls aged 16 to 18 years in Riyadh to engage in smoking (Al Ghobain et al. 2011). Male secondary school students in Saudi Arabia mostly began smoking at the early age of 14 years or younger (Fida and Abdelmoneim 2013). In fact, having a close friend who smokes was found to be the strongest predictor of smoking among students in the Kingdom (Al-Bedah et al. 2010; Beaver et al. 2016). These results are are consistent with findings involving adolescents adolescents in Madinah city, as the prevalence was higher among those who had parents and friends who smoked (Al-Zalabani 2015).

In our study, it was noticeable that with each year's increase in age, the odds of smoking increased 1.61 times. In a study carried out by Mandil et al. (2011), the authors identified age as a significant predictor of smoking among undergraduate students. They found that the 17-year-olds in the group were more likely to be smokers than the 16-year-olds in the group. These age groups are most noticeable in terms of practice smoking in the High Schools of Saudi Arabia. In fact, one in five adolescents from 14 to 19 years of age practice smoking. As their age increases, smoking habits also increases. According to a study in Riyadh Saudi Arabia, high school students have high prevalence of waterpipe smoking among males and females. Waterpipe smoking is a traditional way of smoking in Saudi Arabia, known as Shisha, where tobacco is warmed, then the fumes passed via an elastic hosepipe to the mouth. In addition, it was noted that smoking was common among those in early adulthood (Al Moamary et al. 2012). In the study of Al Ghobain et al. (2011), the prevalence of smoking among the group aged 16 to 18 years in Saudi Arabia was approximately $50 \%$. A similar age range has been identified as the commencement age of smoking 
among male medical students in Saudi Arabia (Taha et al. 2010). Furthermore, reports have revealed that among female college students in the Kingdom, smoking starts at a mean age of $16 \pm 2.4$ years (Koura et al. 2011). These consistent findings emphasize the significance of directing the efforts towards this age group.

In a city with the HCP, we found that the odds of having a smoker in the adolescents' family were 1.73 times higher than in the other cities. It was reported in the study by Al-Mohamed and Amin (2010) that having a family member who smoked, irrespective of their friends, was one of the most common significant predictors to smoking among male university students. Furthermore, nearly $50 \%$ of the respondents in their study were smoking. The influence of a family member on smoking in Saudi Arabia has been reported in other studies such as those of Almogbel et al. (2013); Mandil et al. (2011) and AlTurki and Al-Rowais (2008b). Most of these studies emphasized the importance of parental influence in smoking. The fathers were mostly cited as the smoker in the family rather than the mothers (Mandil et al. 2011). In a study conducted in the Kingdom among male secondary school students, both family members and smoker friends were the most significant influencers (Fida and Abdelmoneim 2013). These studies support our finding of a high percentage of family and friends in those who smoked. It is worth mentioning that a study in Madinah reported that most second-hand smoking is experienced by adolescents outside their homes (Al-Zalabani et al. 2015). Similarly, according to the study by Park et al. (2012), adolescents who spent most of the time outside their homes, were more likely to engage in smoking. However, the home environment was also perceived as a source of second-hand smoking. For instance, the study by Al-Zalabani et al. (2015) noted that both, parents at home, and friends who were commonly gathered outside, were the highest risk factors for passive smoking.

According to the reviewed literature, most adolescents in Northern Saudi Arabia claimed to smoke between four and ten cigarettes per day (Algorinees et al. 2016). A study conducted by Al Nohair (2011) reported that secondary school students in Saudi Arabia were influenced by watching teachers smoke. In addition, they most common reason for their smoking was to relieve stress and to fill their spare time. Other determinants for smoking among adolescents in the Kingdom were high family income or belonging to wealthy families (Mohammed et al. 2014). Other research has suggested that perceptions of the effects of smoking on health, and the religious beliefs were barriers to smoking among medical students in Riyadh Saudi Arabia (Al-Turki and Al-Rowais 2008a). Although the present study did not investigate religious beliefs regarding smoking, it did find that most of the subjects in both city programs were aware that smoking is harmful to health.

Another advantage of the health program is the relatively superior knowledge of smoking among enrolled subjects in the healthy cities compared to those in the non-healthy cities. Of note, $47.8 \%$ of participants from the healthy cities had been exposed to anti-smoking campaigns versus only $40 \%$ in the non-healthy cities. Nonetheless, the prevalence of smoking in participants from healthy cities was markedly higher than in those from non-healthy cities 
A limitation encountered when conducting the study was that the sample population was composed of adolescents in high schools aged between 15 and 19 years. The study did not take into account any adolescents not attending school. Hence, for a thorough understanding of the smoking behaviours of Saudi Arabian adolescents, research should include adolescents between the ages of 10 and 19 irrespective of their schooling status.

\section{Conclusion}

The findings showed that gender, the presence of an influencer, having a smoker friend, and smoker family member significantly contributed to predicting smoking behaviour. The characteristics of the adolescents relevant to smoking were found to significantly vary between those within the program and those who were not. The health program may be effective; however, future evaluation should consider recent research inferences and approaches to derive more meaningful results.

\section{Declarations}

Ethics approval and consent to participate: We received ethical approval from the Human Research Ethics Committee, University of New England, Armidale NSW 2351, Australia (approval no: HE17-021). Approval was also received from the Ministry of Education, Saudi Arabia. All participants gave their written informed consent.

Consent for publication: not applicable

Availability of data and materials: Data is available from the corresponding author on reasonable request.

Competing interests: The authors declare that they have no competing interests

Funding: Not applicable

\section{References}

Al-Bedah AM, Qureshi NA, Al-Guhaimani HI, Basahi JA (2010) The Global Youth Tobacco Survey - 2007. Comparison with the Global Youth Tobacco Survey 2001-2002 in Saudi Arabia. Saudi medical journal 31:1036-1043

Al-Kaabba AF, Saeed AA, Abdalla AM, Hassan HA, Mustafa AA (2011) Prevalence and associated factors of cigarette smoking among medical students at King Fahad Medical City in Riyadh of Saudi Arabia. Journal of family \& community medicine 18:8-12 doi:10.4103/1319-1683.78631

Al-Makadma AS, Moynihan M, Dobson S, Saewyc E (2015) Tobacco use among adolescents in Riyadh Saudi Arabia Int J Adolesc Med Health 27(3):357-60 doi: 10.1515/ijamh-2014-0023 
Al-Mohamed HI, Amin TT (2010) Pattern and prevalence of smoking among students at King Faisal University, Al Hassa, Saudi Arabia East Mediterr Health J 16(1):56-64

Al-Turki YA, Al-Rowais NA (2008a) Prevalence of smoking among female medical students in the College of Medicine, Riyadh, Saudi Arabia Saudi medical journal 29:311-312

Al-Turki YA, Al-Rowais NA (2008b) Prevalence of smoking among female medical students in the College of Medicine, Riyadh, Saudi Arabia. Saudi medical journal 29:311-312

Al-Zalabani A, Kasim K (2015) Prevalence and predictors of adolescents' cigarette smoking in Madinah, Saudi Arabia: a school-based cross-sectional study BMC Public Health 15:17 doi:10.1186/s12889-0151363-8

Al-Zalabani AH (2015) Family Context Factors and the Risk of Smoking among Male Adolescents in Saudi Arabia. Asian Pacific journal of cancer prevention : APJCP 16:5847-5852

Al-Zalabani AH, Amer SM, Kasim KA, Alqabshawi RI, Abdallah AR (2015) Second-Hand Smoking among Intermediate and Secondary School Students in Madinah, Saudi Arabia. BioMed research international 2015:672393 doi:10.1155/2015/672393

Al Agili DE, Park H-K (2012) The Prevalence and Determinants of Tobacco Use Among Adolescents in Saudi Arabia Journal of School Health 82:131-138 doi:10.1111/j.1746-1561.2011.00676.x

Al Ghobain MO, Al Moamary MS, Al Shehri SN, Al-Hajjaj MS (2011) Prevalence and characteristics of cigarette smoking among 16 to 18 years old boys and girls in Saudi Arabia. Annals of thoracic medicine 6:137-140 doi:10.4103/1817-1737.82447

Al Moamary MS, Al Ghobain MA, Al Shehri SN, Alfayez Al, Gasmelseed AY, Al-Hajjaj MS (2012) The prevalence and characteristics of water-pipe smoking among high school students in Saudi Arabia $J$ Infect Public Health 5(2):159-68 doi: 10.1016/j.jiph.2012.01.002

Al Nohair SF (2011) Prevalence of smoking and its related behaviors and beliefs among secondary school students in Riyadh, Saudi Arabia Int J Health Sci(Qassim) 5(1): 51-57

Al Nohair SF (2017) Epidemiology of Cigarette Smoking among Adolescent Male Students in Qassim, Saudi Arabia Public Health Research 7(5):119-122 doi:10.5923/j.phr.20170705.03

Algorinees RM et al. (2016) Prevalence of cigarette smoking usage among adolescent students in northern saudi arabia Asian Pac J Cancer Prev 17:3839-3843

Almogbel YS, Abughosh SM, Almogbel FS, Alhaidar IA, Sansgiry SS (2013) Predictors of smoking among male college students in Saudi Arabia East Mediterr Health J 19(11):909-14 
Alsubaie ASR (2018) Prevalence and determinants of smoking behavior among male school adolescents in Saudi Arabia Int J Adolesc Med Health doi:10.1515/ijamh-2017-0180

Amin TT, Amr MAM, Zaza BO, Suleman W (2010) Harm perception, attitudes and predictors of waterpipe (shisha) smoking among secondary school adolescents in Al-Hassa, Saudi Arabia. Asian Pacific journal of cancer prevention : APJCP 11:293-301

Ansari K, Farooqi FA (2017) Comparison and prevalence of smoking among Saudi females from different Departments of the College of Applied Medical Sciences in Dammam Int J Health Sci(Qassim) 11(5):5662

Beaver KM, Al-Ghamdi MS, Kobeisy AN, Alqurashi FH, Schwartz JA, Connolly EJ, Gajos JM (2016) The Effects of Low Self-Control and Delinquent Peers on Alcohol, Tobacco, and Drug Use in a Sample of Saudi Arabian Youth Int J Offender Ther Comp Criminol 60(13):1569-87 doi:

$10.1177 / 0306624 X 15583670$

Chapman S, MacKenzie R (2012) There's nothing that succeeds like failure: discerning the woods from the trees in smoking cessation debates Nicotine \& tobacco research 15:750-751

Fida, Abdelmoneim I (2013) Prevalence of smoking among male secondary school students in Jeddah, Saudi Arabia Journal of Family and Community Medicine 20:168 doi:10.4103/2230-8229.121993

GAS (2015) Population in The Kingdom by Single Age ,Nationality and Gender. http://www.stats.gov.sa/en/3131.

Koura M, Bahnassy A, Al-Dossary A (2011) Smoking pattern among female college students in Dammam, Saudi Arabia Journal of Family and Community Medicine 18:63 doi:10.4103/2230-8229.83370

Mandil A, BinSaeed A, Dabbagh R, Shaikh SA, AlSaadi M, Khan M (2011) Smoking among Saudi university students: consumption patterns and risk factors East Mediterr Health J 17(4):309-16

Mohammed M, Eggers SM, Alotaiby FF, de Vries N, de Vries H (2018) Smoking uptake among Saudi adolescents: tobacco epidemic indicators and preventive actions needed Glob Health Promot 25(2):6-15 doi: $10.1177 / 1757975914548193$

$\mathrm{Ng}$ M et al. (2014) Smoking prevalence and cigarette consumption in 187 countries, 1980-2012 JAMA 8;311(2):183-92 doi: 10.1001/jama.2013.284692

Park HK, Al Agili DE, Bartolucci A (2012) Factors Affecting Tobacco Use Among Middle School Students in Saudi Arabia Maternal and Child Health Journal 16:1828-1836 doi:10.1007/s10995-011-0929-z

So ES, Yeo JY (2015) Factors associated with early smoking initiation among Korean adolescents Asian Nurs Res (Korean Soc Nurs Sci) 9(2):115-9 doi: 10.1016/j.anr.2015.05.002 
Taha AZ, Sabra AA, Al-Mustafa ZZ, Al-Awami HR, Al-Khalaf MA, Al-Momen MM (2010) Water pipe (shisha) smoking among male students of medical colleges in the eastern region of Saudi Arabia. Annals of Saudi medicine 30:222-226 doi:10.4103/0256-4947.62838

\section{Tables}

Table 1. Characteristics of participants $(n=1108)$ 


\begin{tabular}{|c|c|c|c|c|}
\hline \multirow[t]{2}{*}{ Characteristics } & \multicolumn{2}{|c|}{$\begin{array}{c}\text { NHC } \\
(\underline{N=750)} .\end{array}$} & \multicolumn{2}{|c|}{$\begin{array}{c}\mathrm{HC} \\
(\underline{\mathrm{N}=358})\end{array}$} \\
\hline & $\mathrm{F}$ & $\%$ & F & $\%$ \\
\hline \multicolumn{5}{|l|}{ Gender } \\
\hline Male & 336 & 44.80 & 164 & 45.81 \\
\hline Female & 414 & 55.20 & 194 & 54.19 \\
\hline \multicolumn{5}{|l|}{ Age in years } \\
\hline 15 years old & 29 & 3.87 & 13 & 3.63 \\
\hline 16 years old & 251 & 33.47 & 118 & 32.96 \\
\hline 17 years old & 283 & 37.73 & 111 & 31.01 \\
\hline 18 years old & 148 & 19.73 & 93 & 25.98 \\
\hline 19 years old & 39 & 5.20 & 23 & 6.42 \\
\hline \multicolumn{5}{|l|}{ Education level } \\
\hline Grade 10 & 256 & 34.13 & 122 & 34.08 \\
\hline Grade 11 & 255 & 34.00 & 120 & 33.52 \\
\hline Grade 12 & 239 & 31.87 & 116 & 32.40 \\
\hline \multicolumn{5}{|l|}{ School category } \\
\hline Public & 627 & 83.60 & 317 & 88.55 \\
\hline Private & 123 & 16.40 & 41 & 11.45 \\
\hline \multicolumn{5}{|l|}{ Academic performance } \\
\hline Poor & 3 & 0.40 & 6 & 1.68 \\
\hline Average & 18 & 2.40 & 7 & 1.96 \\
\hline Good & 87 & 11.60 & 31 & 8.66 \\
\hline Very good & 204 & 27.20 & 90 & 25.14 \\
\hline Excellent & 438 & 58.40 & 224 & 62.57 \\
\hline \multicolumn{5}{|l|}{ Residing with } \\
\hline Not with parents & 14 & 1.87 & 3 & 0.84 \\
\hline Either mother or father & 87 & 11.60 & 40 & 11.17 \\
\hline Both parents & 649 & 86.53 & 315 & 87.99 \\
\hline \multicolumn{5}{|l|}{ Father's education level } \\
\hline No formal education & 123 & 16.40 & 63 & 17.60 \\
\hline At most upper 2ndary educ. & 323 & 43.07 & 138 & 38.55 \\
\hline At least college education & 304 & 40.53 & 157 & 43.85 \\
\hline \multicolumn{5}{|l|}{ Mother's education level } \\
\hline No formal education & 134 & 17.87 & 52 & 14.53 \\
\hline At most upper 2ndary educ. & 353 & 47.07 & 146 & 40.78 \\
\hline At least college education & 263 & 35.07 & 160 & 44.69 \\
\hline
\end{tabular}


Estimated combined monthly family income

\begin{tabular}{lcccc}
\hline No idea & 269 & 35.87 & 134 & 37.43 \\
\hline$\leq 3999$ US\$ & 293 & 39.07 & 107 & 29.89 \\
\hline$\geq 4000$ US\$ & 188 & 25.07 & 117 & 32.68 \\
\hline
\end{tabular}

Table 2. Prevalence of smoking and smoking risk factors among adolescents: a cross-sectional survey, Qassim, Saudi Arabia, April-September 2017

\begin{tabular}{|c|c|c|c|}
\hline Variables & \multicolumn{3}{|c|}{ Prevalence per $100(95 \% \mathrm{CI})$} \\
\hline Current smokers & $8.8(5.9-11.7)$ & $3.5(2.2-4.8)$ & $5.2(3.9-6.5)$ \\
\hline \multicolumn{4}{|l|}{ Male smokers } \\
\hline \multicolumn{4}{|l|}{ Female smokers } \\
\hline Family members smoking & $58(52.9-63.1)$ & $44.3(40.8-47.9)$ & $48.7(45.8-51.6)$ \\
\hline Close friends smoking & $67.3(62.5-72.1)$ & $72.2(69-75.3)$ & $70.6(68-73.3)$ \\
\hline Support banning smoking in public places & $93.7(91.2-96.2)$ & $93(91.2-94.8)$ & $93.2(91.7-94.7)$ \\
\hline Tried to quit smoking & $60.8(46.9-74.7)$ & $69.9(59.1-80.6)$ & $66.1(57.7-74.6)$ \\
\hline Would be able to quit smoking if I wanted to & $40.9(25.8-56)$ & $36.1(22-50)$ & $38.5(28.3-48.6)$ \\
\hline Know where to seek support to quit smoking & $53.3(48.1-58.4)$ & $52(48.5-55.6)$ & $52.4(49.5-55.3)$ \\
\hline Exposed to anti-smoking campaign & $47.8(42.6-53)$ & $40.1(36.6-43.5)$ & $42.5(39.7-45.4)$ \\
\hline Parents discuss the harmful effect of smoking & $51.1(45.9-56.3)$ & $47.6(44.1-51.1)$ & $48.7(45.8-51.6)$ \\
\hline Harmful effect of smoking discussed in school & $86.5(83-90.1)$ & $83(80.3-85.6)$ & $84.1(82-86.2)$ \\
\hline Smokers have more friends & $15.7(11.9-19.4)$ & $16.9(14.3-19.6)$ & $16.5(14.3-18.7)$ \\
\hline Smoking is harmful to health & $97.3(95.6-98.9)$ & $94.9(93.4-96.5)$ & $95.7(94.5-96.9)$ \\
\hline Smoking makes one attractive & $26.6(22.1-31.2)$ & $26.4(23.3-29.5)$ & $26.5(24-29.1)$ \\
\hline Smoking gives feeling of independence & $38.7(33.7-43.8)$ & $30(26.8-33.3)$ & $32.8(30-35.6)$ \\
\hline
\end{tabular}

Table 3. Logistic regression analysis of adolescents' current smoking behaviour by their socio-demographic variables: a cross-sectional survey,

Qassim, Saudi Arabia, April-September 2017 


\begin{tabular}{|c|c|c|c|c|}
\hline Variables & OR $(95 \% \mathrm{CI})$ & Std. Err. & $z$ & $\mathrm{p}>|z|$ \\
\hline Gender- Male & 1 & & & \\
\hline Female & $.08(.03-.21)$ & .04 & -5.19 & .000 \\
\hline Age & $1.61(1.25-2.07)$ & .21 & 3.73 & .000 \\
\hline Type of school- Public & 1 & & & \\
\hline Private & 2.33 & .75 & 2.65 & .008 \\
\hline Academic performance- Poor or average & 1 & & & \\
\hline Very good or excellent & .27 & .08 & -4.19 & .000 \\
\hline Living with- Both parents & 1 & & & \\
\hline Father & $1.18(.14-10.16)$ & 1.3 & .15 & .880 \\
\hline Mother & $1.5(.57-3.98)$ & .75 & .82 & .415 \\
\hline Not living with parent & $1.06(.13-8.52)$ & 1.13 & .06 & .955 \\
\hline Father's education- No university degree & 1 & & & \\
\hline University degree & $1.72(.89-3.31)$ & .57 & 1.62 & .105 \\
\hline Mother's education- No university degree & 1 & & & \\
\hline University degree & $1.12(.59-2.08)$ & .36 & .32 & .752 \\
\hline \multicolumn{5}{|l|}{ Nationality- Saudi } \\
\hline Non-Saudi & $.58(.17-1.97)$ & .36 & -.87 & .384 \\
\hline
\end{tabular}

Table 4. Logistic regression analysis of adolescents' current smoking behaviour by the type of city health program: a cross-sectional survey, Qassim, Saudi Arabia, April-September 2017

\begin{tabular}{|c|c|c|c|c|}
\hline Variables & OR $(95 \% \mathrm{CI})$ & Std. Err. & $z$ & $p>|z|$ \\
\hline Cities running healthy city program- No & 1 & & & \\
\hline Yes & $3.03(1.7-5.4)$ & 0.89 & 3.77 & 0.000 \\
\hline Type of school- Public & 1 & & & \\
\hline Private & $2.66(1.41-5.06)$ & 0.87 & 3.02 & 0.003 \\
\hline Academic performance- Poor or average & 1 & & & \\
\hline Very good or excellent & $0.29(0.16-0.53)$ & 0.09 & -4.06 & 0.000 \\
\hline Gender- Male & 1 & & & \\
\hline Female & $0.08(0.03-0.21)$ & 0.04 & -5.17 & 0.000 \\
\hline Age & $1.59(1.23-2.05)$ & 0.89 & 3.55 & 0.000 \\
\hline
\end{tabular}


Table 5. Odds of smoking risk factors among adolescents in the city health program: a cross-sectional survey, Qassim, Saudi Arabia, April-

September 2017

\begin{tabular}{ll}
\hline Smoking risk factors & OR in the health cities (95\% CI) \\
\hline Family members smoking & $1.73(1.35-2.23)$ \\
Close friends smoking & $1.26(.96-1.65)$ \\
\hline Support banning smoking in public places & $1.12(.68-1.85)$ \\
\hline Tried to quit smoking & $.67(.32-1.42)$ \\
\hline Would be able to quit smoking if I wanted to & $1.22(.52-2.85)$ \\
\hline Know where to seek support to quit smoking & $1.05(.82-1.35)$ \\
\hline Exposed to anti-smoking campaign & $1.37(1.07-1.76)$ \\
\hline Parents discuss the harmful effect of smoking & $1.15(.90-1.48)$ \\
\hline Harmful effect of smoking discussed in school & $1.31(.93-1.88)$ \\
\hline Smokers have more friends & $.91(.65-1.28)$ \\
\hline Smoking is harmful to health & $1.89(.93-3.83)$ \\
\hline Smoking makes one attractive & $1.01(.76-1.34)$ \\
\hline Smoking gives feeling of independence & $1.47(1.13-1.91)$ \\
\hline
\end{tabular}

